\title{
Retrospective study of intentional tooth replantation
}

\author{
Joo-Hyuck Park' ${ }^{1}$, Sel Ae Hwang ${ }^{2}$, Suk-Ja Yoon², Byung-Cheol Kang ${ }^{2}$, Kyung-Min Lee ${ }^{3}$, and Jae-Seo Lee ${ }^{2 *}$ \\ ${ }^{1}$ Department of Dental science, Graduate School, Chonnam National University, Gwangju 61186, Republic of Korea \\ ${ }^{2}$ Department of Oral and Maxillofacial Radiology, School of Dentistry, Chonnam National University, Gwangju 61186, \\ Republic of Korea \\ ${ }^{3}$ Department of Orthodontics, School of Dentistry, Chonnam National University, Gwangju 61186, Republic of Korea
}

(Received Oct 30, 2017; Revised version received Nov 10, 2017; Accepted Nov 11, 2017)

\begin{abstract}
This retrospective study investigated the effects of preoperative radiographic characteristics and the causes of intentional replantation on treatment outcome. The records of fifty patients who had undergone intentional replantation at the dental clinic of Chonnam National University from 2009 to 2016 were examined. Age, sex, tooth location, diagnosis, and preoperative radiographs were analyzed using PACS (Picture Archiving Communication System) and IBM SPSS Statistics 23.0. Eighteen (36\%) subjects were female and 32 (64\%) were male. The mean age at the time of surgery was 39.1 years $( \pm 16.4)$, and the mean periodic follow-up period was 18.8 months $( \pm 15.6)$. Pulp and periapical diseases were the most common cause of disease (31 cases). The preoperative radiologic characteristics were 9 cases (18\%) without lesion, 2 cases (4\%) with apical periodontal ligament (PDL) space widening, 29 cases (58\%) with periapical rarefaction, 10 cases $(20 \%)$ with periradicular rarefaction and 28 cases $(56 \%)$ of condensing osteitis. The survival rate of the intentionally replanted teeth was $78 \%$ and the failure rate was $22 \%$. The expected survival time of the teeth was 44.1 months. Data were evaluated according to frequency distribution and the chi-squared test. Fisher's exact test was used to investigate statistical significances $(p<0.05)$ between healed tooth versus extracted tooth after intentional replantation. There was no statistically significant difference between the success rate and failure rate of intentional replantation based on age, gender, teeth, diagnosis, filling material, fixation method, preoperative proximal radiolucency or lesion size.
\end{abstract}

KEY WORDS: Radiography, Replantation, Tooth

\section{서 론}

근관 치료는 전통적인 치수 원인 치근단 병소의 치료 방 법으로, 78.9 85.1\%의 성공률을 보인다[1,2]. 근관 치료가 실패하는 경우에 재근관 치료를 시행하지만[3], 근단부 병 소의 크기에 따라 $75 \%$ 정도의 성공률을 보여[4] 재근관 치료도 실패할 가능성이 있다. 재근관치료마저 실패한 경 우엔 수술적 근관 치료를 고려해야 하는데, 이 중 하나가 의도적 재식술이다.

의도적 재식술은 기구 접근이 어려운 치아에서 발치 후 구외에서 근관 충전을 실시한 후 발치와에 다시 식립

\footnotetext{
*Corresponding author: Jae-Seo Lee

Department of Oral and Maxillofacial Radiology, School of Dentistry, Dental Science Research Institute, Chonnam National University, 77 Yongbong-ro, Buk-gu, Gwangju 61186, Republic of Korea Tel.: +82-82-560-5686, Fax: +82-62 -530-5679

E-mail: jsyi16@hanmail.net
}

하는 술식이다[5, 6]. 치근첨으로의 접근이 용이하여 보다 향상된 치근첨 폐쇄를 얻을 수 있으며, 주변 골에 대한 손 상이 적으면서 연조직 침범이 적기 때문에, 술 후 불편감 이 적다. 또한, 자칫 놓치기 쉬운 치아 파절선을 직접 확 인할 수 있으며, 치근첨수술에 비해 비용이 저렴하다는 장 점이 있다[7]. 그러나 치근 만곡이나 치근이개가 있는 치 아는 발치 과정 중에 치근 파절의 위험성이 있어 의도적 재식술에 적합하지 않고, 보철물이 있는 경우엔 제거해야 하며, 술 후에 치근 흡수나 유착이 일어날 수 있다는 단점 도 있다[7]. 자연치아를 유지한다는 관점에선 임플란트보 다 장점이 있는 술식이다. 의도적 재식술의 경과 관찰에 관한 논문들[8-12]은 있지만, 의도적 재식술을 시행하기 전 치아의 치근단방사선사진에 대한 소견과 의도적 재식 술을 시행한 원인을 분석한 연구는 많지 않았다. 그러므로 본 연구의 목적은 의도적 재식술을 시행한 치아들의 술 전 방사선학적 특징과 재식술을 시행한 원인을 분석하고, 치 료 결과에 미치는 영향과 생존율을 조사해보고자 한다. 


\section{재료 및 방법}

연구 대상은 2009년 1월부터 2016년 12월까지 전남대학 교치과병원에서 의도적 재식술을 시행 받은 환자를 대상 으로 하였다.

전남대학교치과병원 PACS (Picture archiving and communication system)에서 "study comments"에 intentional replantation 을 입력하여 증례를 찾았다. 검색 결과들의 전자의무기록을 확인하여 실제 의도적 재식술을 시행 받은 환자들을 2 차 선 별하고, 이 환자들의 전자의무기록에서 수술 당시의 나이, 성 별, 시술 치아, 진단명, 수술 시 사용한 충전 재료, 고정 종류 와 기간, 경과 관찰 기간, 그리고 치아 별 마지막 기록을 확 인하여 생존, 실패로 나누어 정리하였다. 정리한 자료를 바탕 으로 경과 관찰 기간이 2 개월 이상인 환자들의 자료들만 다 시 정리하였다.

진단명은 WHO (world health organization)에서 제시한 ‘치과질환의 국제분류'에 따라서 세부 진단명으로 분류하 였고[13], 분석을 위하여 다시 큰 범주로 통합하였다.

$\mathrm{PACS}$ 를 이용하여, 의도적 재식술을 시행하기 전의 치근 단 방사선 사진에서 치근단 병소 유무에 따라 다음 4 단 계로 나누어 기록하였다. 방사선 투과상이 관찰되지 않는 경우는 Grade 1 로, 근첨 치주인대강의 확장은 Grade 2로, 근단부에 국한된 방사선 투과성 병소는 Grade 3, 치근 전
체를 둘러싼 방사선 투과성 병소는 Grade 4 로 분류하였고 (Fig. 1), 경화성 골염 존재 여부도 조사하였다. 그리고 치 근단투과성 병소가 있는 경우, 병소의 크기를 각각 가로, 세로로 나누어 길이를 $\mathrm{mm}$ 단위로 측정하였다.

최종 수집한 데이터를 IBM SPSS Statistics 23 (SPSS Inc, Chicago, IL, USA)를 이용하여 분석하였다. 통계에는 교차분석 Fisher's exact test(유의수준 <0.05)와 KaplanMeier 생존 곡선을 이용하였다.

\section{결 과}

대상 환자는 총 50 명, 대상 치아는 50 개였다. 여성이 18 명 $(36 \%)$, 남성이 32 명 $(64 \%)$ 이었다. 환자들의 수술 당시 평균 나이는 $39.1 \pm 16.4$ 세였으며, 시술 부위별로는 상악 19 증례, 하악 31 증례였고, 치아부위별로는 전치부 5 개, 소구치부 2 개, 대구치부 43 개 증례였다. 술 후 경과 관찰 시(평균 18.8 개월, 최대 63 개월) 특이사항이 없는 경우엔 '생존', 경과 관찰하여 발치한 경우엔 '실패’로 기록하였다. 각 변수별 총 치아 개수 중 생존 개수를 생존율, 변수별 총 치아 개수 중 실패 개수를 실패율로 정의하였다. 40 49 세 환자들의 실패율이 $57.1 \%$ 로 다른 연령대에 비해 가장 높은 실패율을 보였다. 많이 사용된 충전 재료는 MTA (mineral trioxide aggregate)이었으며, 고정 방법은 봉합사

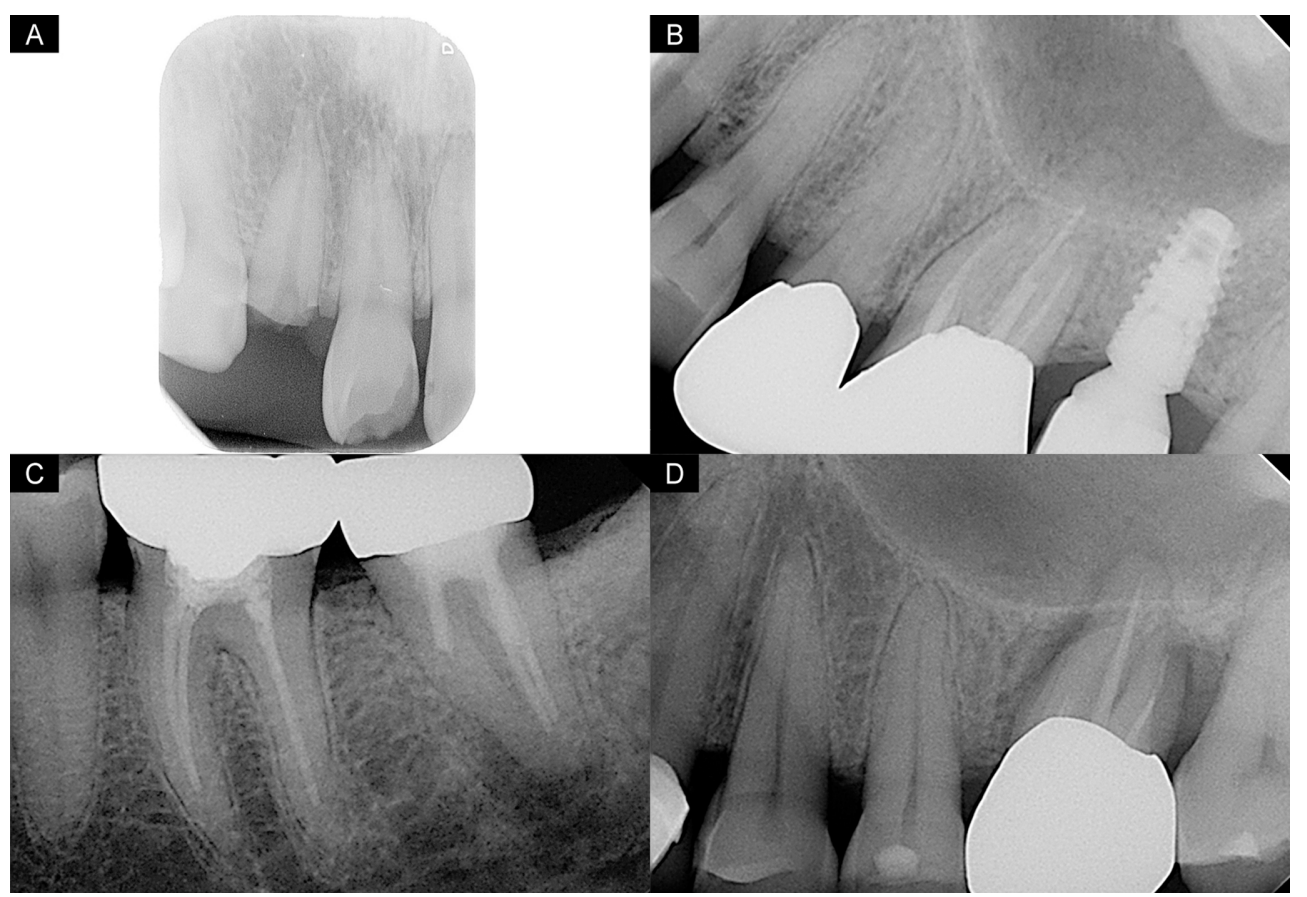

Fig. 1. Classification of radiographic features on periapical radiographs. (A) Grade 1, There is no periapical rarefaction around the root of \#12. (B) Grade 2, The apical PDL space widening is shown in \#26 distal root. (C) Grade 3, The periapical rarefaction is observed in the root of \#37 tooth. (D) Grade 4, Periradicular rarefaction around the \#26 root. 
Table 1. Success rates according to variables

\begin{tabular}{|c|c|c|c|c|}
\hline Variables & $\begin{array}{c}\text { Survival } \\
(\%)\end{array}$ & $\begin{array}{r}\text { Loss } \\
(\%)\end{array}$ & $\begin{array}{c}\text { Total } \\
(\%)\end{array}$ & $p$-value ${ }^{\alpha}$ \\
\hline Sex & & & & 0.724 \\
\hline Female & $15(83.3)$ & $3(16.7)$ & $18(100)$ & \\
\hline Male & $24(75.0)$ & $8(25.0)$ & $32(100)$ & \\
\hline Age & & & & 0.256 \\
\hline$\leq 19$ & $3(100)$ & 0 & $3(100)$ & \\
\hline $20 \sim 29$ & $12(92.3)$ & $1(7.7)$ & $13(100)$ & \\
\hline $30 \sim 39$ & $6(85.7)$ & $1(14.3)$ & $7(100)$ & \\
\hline $40 \sim 49$ & $3(42.9)$ & $4(57.1)$ & $7(100)$ & \\
\hline $50 \sim 59$ & $7(77.8)$ & $2(22.2)$ & $9(100)$ & \\
\hline $60 \sim 69$ & $7(70.0)$ & $3(30.0)$ & $10(100)$ & \\
\hline $70 \leq$ & $1(100)$ & 0 & $1(100)$ & \\
\hline Jaw & & & & 0.727 \\
\hline Maxilla & $14(73.7)$ & $5(26.3)$ & $19(100)$ & \\
\hline Mandible & $25(80.6)$ & $6(19.4)$ & $31(100)$ & \\
\hline Tooth & & & & 1 \\
\hline Incisors & $4(80.0)$ & $1(20.0)$ & $5(100)$ & \\
\hline Premolars & $2(100)$ & 0 & $2(100)$ & \\
\hline Molars & $33(76.7)$ & $10(23.3)$ & $43(100)$ & \\
\hline Filling material & & & & 1 \\
\hline IRM & $2(100)$ & 0 & $2(100)$ & \\
\hline MTA & $34(77.3)$ & $10(21.7)$ & $44(100)$ & \\
\hline Splint & & & & 0.672 \\
\hline Resin Wire Splint & $11(78.6)$ & $3(21.4)$ & $14(100)$ & \\
\hline Suture Splint & $17(85.0)$ & $3(15.0)$ & $20(100)$ & \\
\hline Splint period & & & & 0.246 \\
\hline 1 week & $11(78.6)$ & $3(21.4)$ & $14(100)$ & \\
\hline 2 weeks & $4(100)$ & 0 & $4(100)$ & \\
\hline 3 weeks & $4(100)$ & 0 & $4(100)$ & \\
\hline 4 weeks & $1(50.0)$ & $1(50.0)$ & $2(100)$ & \\
\hline 7 weeks & $1(50.0)$ & $1(50.0)$ & $2(100)$ & \\
\hline 12 weeks & $1(100)$ & 0 & $1(100)$ & \\
\hline 16 weeks & 0 & $1(100)$ & $1(100)$ & \\
\hline
\end{tabular}

${ }^{a} p$-value for Fisher'sexact test, $\alpha=0.05$.
고정을 많이 사용하였다. 고정 기간은 1 16주의 분포를 보였 지만, 가장 많은 고정 기간은 1 주 $(\mathrm{n}=14)$ 였다(Table 1).

의도적 재식술을 시행하게 된 질병명은 '치수 및 치근단 주위 조직의 질환'이 31 건(62\%)로 가장 많았고, ‘치은염 및 치주질환'이 6건(12\%), ‘치아의 파절'이 6건(12\%)으로 뒤따랐다. 이 중 '치은염 및 치주질환'과 '치아의 파절'의 실패율이 각각 $50 \%, 33.3 \%$ 로 다른 변수들보다도 높은 실 패율을 보였다.

세부 진단명으로는 ‘동이 있는 근단주위농양' 12 건 (24\%), ‘동이 없는 근단주위농양' 11 건( $22 \%$ ), ‘치아의 파절' 6 건( $12 \%$ ), '만성 근단 치주염' 5 건(10\%), '만성 치주염' 4건 (8\%) 순으로 나타났다(Table 2).

술 전 치근단 방사선 사진을 평가하여, 방사선 투과성 병소의 유무와 특징, 경화성 골염의 유무와 투과성 병소의 가로와 세로 크기에 따라 의도적 재식술의 성공률과 실패 율을 조사하였다(Fig. 1, Table 3).

술 전 치근단방사선사진의 특징을 비교해보면, 방사선 투과상이 관찰되지 않는 경우'에서 의도적 재식술의 실패 율이 $11.1 \%(\mathrm{n}=1)$ 이었고, '치근 전체를 둘러싼 방사선 투 과성 병소가 있는 치아’의 의도적 치아 재식술의 실패율은 $40 \%(n=4)$ 이었다. 방사선학적 특징과 병소의 크기에 따라 의도적 재식술의 성공률과 실패율을 비교했을 때, 통계학 적으로 유의한 차이는 관찰되지 않았다(Table 3).

Kaplan-Meier 생존 함수를 통해 1년 생존율은 85.9\%, 2 년 생존율은 $70.5 \%$ 를 얻었다. 예상 생존 기간은 44.1 개월 이었다(Fig. 2).

평균 경과 관찰 기간은 $18.8 \pm 15.6$ 개월 이었다. 마지막 경과 관찰 결과를 토대로 빈도 분석한 결과는 생존율 $78 \%$ $(n=39)$, 실패율 $22 \%(n=11)$ 이었다.

Table 2. Success rates according to diagnosis

\begin{tabular}{|c|c|c|c|}
\hline Diagnosis Sub diagnosis & Survival (\%) & Loss $(\%)$ & Total $(\%)$ \\
\hline \multicolumn{4}{|l|}{ Disorders of tooth development and eruption } \\
\hline Dens evaginatus & $1(100)$ & 0 & $1(100)$ \\
\hline \multicolumn{4}{|l|}{ Dental caries } \\
\hline Caries extending into dentine & $1(100)$ & 0 & $1(100)$ \\
\hline Caries of cementum & $2(100)$ & 0 & $2(100)$ \\
\hline \multicolumn{4}{|l|}{ Diseases of pulp and periapical tissues } \\
\hline Acute apical periodontitis of pulpal origin & $2(100)$ & 0 & $2(100)$ \\
\hline Chronic apical periodontitis & $4(80.0)$ & $1(20.0)$ & $5(100)$ \\
\hline Periapical abscess with sinus & $9(75.0)$ & $3(25.0)$ & $12(100)$ \\
\hline Periapical abscess without sinus & $9(81.8)$ & $2(18.2)$ & $11(100)$ \\
\hline Other and unspecified diseases of pulp and periapical tissues & $1(100)$ & 0 & $1(100)$ \\
\hline \multicolumn{4}{|l|}{ Gingivitis and periodontal diseases } \\
\hline Acute periodontitis & $1(50.0)$ & $1(50.0)$ & $2(100)$ \\
\hline Chronic periodontitis & $2(50.0)$ & $2(50.0)$ & $4(100)$ \\
\hline Calcifying odontogenic cyst & $1(100)$ & 0 & $1(100)$ \\
\hline Fracture of tooth & $4(66.7)$ & $2(33.3)$ & $6(100)$ \\
\hline
\end{tabular}


Joo-Hyuck Park et al.

Table 3. Success rates according to radiographic features

\begin{tabular}{|c|c|c|c|c|}
\hline Variables & Survival (\%) & Loss $(\%)$ & Total $(\%)$ & $p$-value ${ }^{\alpha}$ \\
\hline Radiolucency & & & & 0.445 \\
\hline None & $8(88.9)$ & $1(11.1)$ & $9(100)$ & \\
\hline Apical PDL space widening & $2(100)$ & 0 & $2(100)$ & \\
\hline Periapical rarefaction & $23(79.3)$ & $6(20.7)$ & $29(100)$ & \\
\hline Periradicular rarefaction & $6(60.0)$ & $4(40.0)$ & $10(100)$ & \\
\hline Condensing osteitis & & & & 0.589 \\
\hline None & $17(77.3)$ & $5(22.7)$ & $22(100)$ & \\
\hline Yes & $22(78.6)$ & $6(21.4)$ & $28(100)$ & \\
\hline The horizontal size of the lesion & & & & 1 \\
\hline$<5.0 \mathrm{~mm}$ & $6(75.0)$ & $2(25.0)$ & $8(100)$ & \\
\hline $5.00 \sim 9.99 \mathrm{~mm}$ & $20(74.1)$ & $7(25.9)$ & $27(100)$ & \\
\hline $10.00 \sim 14.99 \mathrm{~mm}$ & $3(75.0)$ & $1(25.0)$ & $4(100)$ & \\
\hline The vertical size of the lesion & & & & 1 \\
\hline$<5.0 \mathrm{~mm}$ & $5(71.4)$ & $2(28.6)$ & $7(100)$ & \\
\hline $5.00 \sim 9.99 \mathrm{~mm}$ & $19(76.0)$ & $6(24.0)$ & $25(100)$ & \\
\hline $10.00 \sim 14.99 \mathrm{~mm}$ & $4(80.0)$ & $1(20.0)$ & $5(100)$ & \\
\hline $15.00 \sim 19.99 \mathrm{~mm}$ & 0 & 0 & 0 & \\
\hline $20.00 \mathrm{~mm} \leq$ & $1(100)$ & 0 & $1(100)$ & \\
\hline
\end{tabular}

${ }^{a} p$-value for Fisher'sexact test, $\alpha=0.05$.

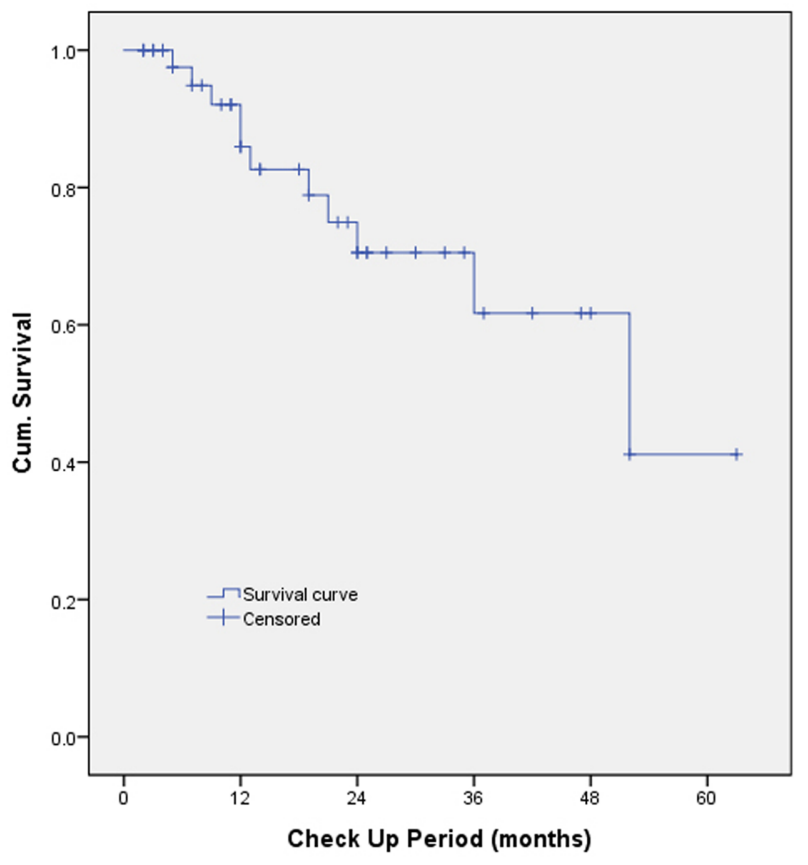

Fig. 2. Kaplan-Meier survival function curve.

\section{고 찰}

본 연구에서는 의도적 재식술을 받은 치아들을 경과 관 찰 결과에 따라 생존, 실패로 나누어 정리한 결과 생존율 은 $78 \%$ 이었다.
이는 국내에서 보고한 다른 논문들(82 95\%)[14-16]과 비교하였을 때, 낮은 수치이지만 다른 논문들 속 표본 구 성의 차이와 표본의 숫자 차이에서 기인하는 것으로 생각 된다.

나이에 따른 의도적 재식술 후 생존율에 대한 논문들이 보고되었는데, 나이가 중요한 요소가 아니라는 결과도 있 었고 $[10,12]$, 치주낭이 존재하는 치아에서는 나이가 생존 율에 영향을 미친다는 논문도 있었다[8]. 본 연구에서는 술 전에 치주낭의 유무에 관한 기록을 확인할 수 없었고, 나이와 관련하여 유의미한 통계 결과 $(p=0.256)$ 도 찾을 수 없었다. 하지만 40 대에서 실패율이 $57.1 \%(\mathrm{n}=4)$ 로 $50 \%$ 가 넘는 비율을 보이므로, 의도적 재식술 시행단계에서 주의 를 기울일 필요가 있다.

이번 연구에서 전체 50 증례 중에 16 증례는 고정에 대 한 기록이 존재하지 않았으며, 방사선 사진 조사에서도 실 제 고정에 대한 실시 여부를 확인할 수 없었다. 의도적 재 식술 후에 고정이 꼭 필요하지 않다는 보고[17-19]도 있었 지만, 치아와 연조직의 재부착이 용이하게 하기 위해 고정 이 필요하다는 논문도 발표되었다[20]. 본 연구에서 재식 술을 시행한 후 고정하지 않은 치아 16 개 가운데, 5 개가 재 식술에 실패하였는데, 고정을 시행한 치아들에 비해 실패 율(31.3\%)은 높지만, 통계적 유의성을 확인할 수 없었다.

본 연구에서는 의도적 재식술을 시행하게 된 병인에 따 라서 예후가 달라질 수 있을 거로 생각하였고, 참고 논문 을 찾아보려 하였으나, 진단명과 생존율의 관계를 조사한 논문은 찾을 수가 없었다. 본 연구에서, 의도적 재식술을 
진행하게 된 진단명 중 가장 많은 비율을 보인 것은 '치수 와 치근 주위 조직의 질병 $(\mathrm{n}=31,62 \%)$ ' 이었고, 이 중 '치 근단주위농양 질환 $(\mathrm{n}=23,46 \%)^{\prime}$ 이 많이 나타났다. 누공의 유무가 의도적 재식술의 실패율에 통계학적으로 유의한 영향을 미치지 않았다. Cho 등의 연구에서도 누공의 존재 여부가 치근 흡수 $(p=0.853)$ 와 치근 유착 $(p=0.054)$ 에 영향 을 주지 않는다고 보고하였다[10].

치근단 방사선 사진 상에서 관찰되는 방사선 특징에 따 라 4단계로 분류하였는데, 가장 높은 비율을 보인 것은 '근단부에 국한된 방사선 투과성 병소'였다 $(\mathrm{n}=29,58 \%)$. 이들의 생존율은 $79.3 \%$ 로 본 연구의 평균인 $78 \%$ 보다 높 은 생존율을 보였다. 방사선 투과성을 보이지 않는 9 증례 (18\%)는 의도적 재식술의 생존율이 $88.9 \%$ 로 나타났고, 치 근 전체를 둘러싼 방사선 투과성 병소가 있는 10 증례 $(20 \%)$ 는 의도적 재식술의 생존율이 $60 \%$ 로 나타났다. 통계 적으로 유의미한 결과를 얻을 수는 없었지만 치근단방사 선사진에서 방사선 투과상을 나타내는 병소가 커짐에 따 라 실패율도 증가하는 경향을 보였다.

염증성 병소에서 흔히 나타나는 경화성 반응인 경화성 골염은 의도적 재식술의 생존율에 별다른 영향이 없는 것 으로 나타났다. 따라서 오래 지속된 염증성 병소로 인한 골질의 변화가 있더라도, 의도적 재식술을 시행하는 데 있 어 큰 장애요소가 되진 않을 것으로 생각되지만, 향후 더 많은 치아를 대상으로 한 조사가 필요할 것이다.

$5 \mathrm{~mm}$ 단위로 각각 병소의 가로와 세로 크기 변화에 따 라 의도적 재식술을 받은 치아의 생존율을 비교한 결과 통 계적으로 유의한 차이는 없었다. 가로 크기 별에 따른 생 존율은 비슷했지만, 병소의 세로 크기가 커질수록 생존율 이 증가되는 것이 관찰되었다(Table 3).

의도적 재식술의 생존율에 대한 문헌고찰을 한 연구에 서, Torabinejad 등은 4년의 Kaplan-Meier 생존 곡선을 보 인 논문은 단 한 편이었다고 했다[21]. 이전 논문에서 1년 생존율은 $89 \%$ 였지만, 4 년 생존율은 $68 \%$ 로 떨어졌고 예상 생존 기간은 49.56 개월이었다[16]. 본 연구에서도 KaplanMeier 생존 곡선을 그려본 결과 1년 생존율은 $85.9 \%$ 이었 지만, 2 년 생존율 $70.5 \%$ 를 거쳐 4년 생존율은 $41.1 \%$ 였고, 예 상 생존 기간은 44.1 개월이었다. 본 연구에서 평균 추적검 사 기간은 18.8 개월이었다. 이는 다른 논문들 $(25.4,31.2$, 38.4 개월)에 비해서 $[8,10,16]$ 추적검사기간이 부족하였고, 이러한 짧은 경과 관찰 기간이 Kaplan-Meier 생존 곡선의 정확성에 대한 한계점으로 작용할 수 있을 것이다.

의도적 재식술에서 중요한 과정 중 하나는 발치이다. 발 치 도중 치아나 치근이 부러지게 된다면 의도적 재식술이 실패하기 때문이다. 또한, 치근과 발치와에 존재하는 치주 인대를 손상시킬 경우 치근 흡수가 증가하게 된다[22]. Peer은 치주인대손상의 우려 때문에 발치 기자의 사용을
될 수 있으면 피하라고 하였다[7]. Haruyuki은 교정력을 이용하여 동요도를 가하면 치주 인대의 양이 늘어나 회복 에 도움이 된다고 하였고[23], Choi 등은 교정력으로 동 요도를 가한 후 진행한 의도적 재식술에서 교정력의 여부 가 치아 생존율에 유의한 영향 $(p=0.016)$ 이 있다고 보고하 였다[16]. Choi 등의 연구에서는 교정력 없이 의도적 재 식술을 시행한 치아의 생존율은 $83.2 \%$ 지만 교정력을 가 했을 땐 $94.4 \%$ 로 그 확률이 $11 \%$ 가량 더 높은 것으로 나 타났다[16]. 또한, 교정력을 가했을 때 치근 흡수와 치아 파절의 경우를 낮추었다고 보고하였다. 본 연구에서는 발 치에 사용한 도구나 발치 과정에 대한 기록을 확인할 수 없었다.

의도적 재식술을 시행할 때 구강 외 시간은 의도적 재 식술의 성공 여부에 상당한 영향을 미친다고 익히 알려져 왔다. 30 분 정도의 구강 외 노출시간에도 치주 인대 세포 는 손실이 나타난다고 하였다[24, 25]. 구강 외 시간이 15 분이 넘었을 때 유착이 일어날 수 있고, C-모양 근관 치아 의 의도적 재식 생존율이 낮아진다는 보고가 있었지만 $[10,12]$, 관련성이 없었다는 연구 결과도 있다[8]. 본 연구 에서는 구강 외 노출시간에 대한 기록이 존재하지 않아 관 련성을 확인할 수 없었다.

의도적 재식술의 금기증 중 하나는 치주염을 동반한 치 아이다[9]. 하지만 최근의 연구에서 치주 병소가 심한 치 아에서도 의도적 재식술을 통하여 양호한 결과를 얻은 논 문들이 발표되고 있다[20,26]. 본 연구에서도 '치은염 및 치주질환'으로 진단받은 환자에게서 6 증례가 의도적 재식 술을 시행하였는데, 그 중 $50 \%$ 의 생존율을 보였다.

통계적으로 유의미한 수치는 아니었지만, 더 많은 증례 를 조사하여, 치주질환으로 진단받은 치아의 의도적 재식 술에 대한 생존율에 관한 연구가 진행되어야 할 것으로 생 각된다.

\section{Conflict of Interest}

The authors declare that they have no competing interests.

\section{ORCID}

$\begin{array}{ll}\text { Joo-Hyuck Park } & 0003-3849-2015 \\ \text { Sel Ae Hwang } & 0000-0002-1963-3735 \\ \text { Suk-Ja Yoon } & 0000-0001-9975-255 X \\ \text { Byung-Cheol Kang } & 0000-0003-1944-5985 \\ \text { Kyung-Min Lee } & 0000-0003-3102-4550 \\ \text { Jae-Seo Lee } & 0000-0001-8059-0378\end{array}$




\section{References}

1. Kojima K, Inamoto K, Nagamatsu K, Hara A, Nakata K, Morita I, Nakagaki H, Nakamura H. Success rate of endodontic treatment of teeth with vital and nonvital pulps. A meta-analysis. Oral Surg Oral Med Oral Pathol Oral Radiol Endod 2004;97:95-99. doi: 10.1016/S1079210403004803.

2. Dammaschke T, Steven D, Kaup M, Ott KH. Long-term survival of root-canal-treated teeth: A Retrospective study over 10 years. J Endod 2003;29:638-643. doi: 10.1097/00004770-200310000-00006.

3. Friedman S, Mor C. The success of endodontic therapy-healing and functionality. J Calif Dent Assoc 2004;32: 493-503.

4. Sundqvist G, Figdor D, Persson S, Sjögren U. Microbiologic analysis of teeth with failed endodontic treatment and the outcome of conservative re-treatment. Oral Surg Oral Med Oral Pathol Oral Radiol Endod 1998;85:86-93. doi: 10.1016/S1079-2104(98)90404-8.

5. Weine FS. The Case Against Intentional Replantation. J Am Dent Assoc 1980;100:664-668. doi: 10.14219/ jada.archive.1980.0227.

6. Messkoub M. Intentional replantation: A successful alternative for hopeless teeth. Oral Surg Oral Med Oral Pathol 1991;71:743-747.

7. Peer M. Intentional replantation - A "last resort" treatment or a conventional treatment procedure? Nine case reports. Dent Traumatol 2004;20:48-55. doi: 10.1046/ j.1600-4469.2003.00218.x.

8. Cho SY, Lee SJ, Kim ES. Clinical outcomes after intentional replantation of periodontally involved teeth. J Endod 2017;43:550-555. doi: 10.1016/j.joen.2016.11.024.

9. Raghoebar GM, Vissink A. Results of intentional replantation of molars. J Oral Maxillofac Surg 1999;57:240244. doi: 10.1016/S0278-2391(99)90667-5.

10. Cho SY, Lee Y, Shin SJ, Kim E, Jung IY, Friedman S, Lee SJ. Retention and Healing Outcomes after Intentional Replantation. J Endod 2016;42:909-915. doi: 10.1016/j.joen.2016.03.006.

11. Jin MU. Clinical evaluation of intentional replantation. J Korean Dent Assoc 2010;48:288-296.

12. Jang YJ, Lee SJ, Yoon TC, Roh BD, Kim ES. Survival rate of teeth with a c-shaped canal after intentional replantation: A Study of 41 Cases for up to 11 Years. J Endod 2016;42:1320-1325. doi: 10.1016/j.joen.2016.05.010.
13. World Health Organization. Application of the International Classification of Diseases to Dentistry and Stomatology. World Heal Organ. 1995.

14. Choi YH. Short-term clinical outcome of intentionally replanted posterior molars. J Korean Acad Conserv Dent 2011;36:12-18. doi: 10.5395/JKACD.2011.36.1.12.

15. Kim JH, Kim UC, Lee JY, Kim HC, Kim SN. A shortterm clinical study of intentionally replanted posterior molars. J Dent Implant Res 2016;35:33-39.

16. Choi YH, Bae JH, Kim YK, Kim HY, Kim SK, Cho BH. Clinical outcome of intentional replantation with preoperative orthodontic extrusion: a retrospective study. Int Endod J 2014;47:1168-1176. doi: 10.1111/iej.12268.

17. Wallace JA, Vergona K. Epithelial rests' function in replantation: Is splinting necessary in replantation? Oral Surg Oral Med Oral Pathol 1990;70:644-649.

18. Kehoe JC. Splinting and replantation after traumatic avulsion. J Am Dent Assoc 1986;112:224-230. doi: 10.14219/jada.archive.1986.0328.

19. Lu DP. Intentional replantation of periodontally involved and endodontically mistreated tooth. Oral Surg Oral Med Oral Pathol 1986;61:508-513.

20. Demiralp B, Nohutcu RM, Tepe DI, Eratalay K. Intentional replantation for periodontally involved hopeless teeth. Dent Traumatol 2003;19:45-51. doi: 10.1034/j.1600-9657. 2003.00084.x.

21. Torabinejad M, Dinsbach NA, Turman M, Handysides R, Bahjri K, White SN. Survival of intentionally replanted teeth and implant-supported single crowns: A Systematic Review. J Endod 2015;41:992-998. doi: 10.1016/ j.joen.2015.01.004.

22. Trope M. Root resorption due to dental trauma. Endod Top 2002;1:79-100.

23. Haruyuki H. Ortho-transplantation. Seoul: DaehanNarae Publishing; 2006.

24. Söder PO, Otteskog P, Andreasen JO, Modéer T. Effect of drying on viability of periodontal membrane. Eur $\mathrm{J}$ Oral Sci 1977;85:164-168.

25. Modeer T, Dahllof G, Otteskog P. Effect of drying on human periodontal ligament repair in vitro. J Int Assoc Dent Child 1984;15:15-20.

26. Hou G-L, Hou L-T, Weisgold A. Survival rate of teeth with periodontally hopeless prognosis after therapies with intentional replantation and perioprosthetic procedures - a study of case series for 5-12years. Clin Exp Dent Res 2016;2:85-95. doi: 10.1002/cre2.25. 